\title{
A Simple Method for Obtaining Coupled Fixed Points of $\alpha-\psi$-Contractive Type Mappings
}

\author{
Sh. Rezapour ${ }^{1,2}$ and J. Hasanzade Asl ${ }^{1}$ \\ ${ }^{1}$ Department of Mathematics, Science and Research Branch, Islamic Azad University, Tehran, Iran \\ ${ }^{2}$ Department of Mathematics, Azarbaijan Shahid Madani University, Azarshahr, Tabriz, Iran \\ Correspondence should be addressed to Sh. Rezapour; sh.rezapour@azaruniv.edu
}

Received 17 August 2012; Revised 11 October 2012; Accepted 18 October 2012

Academic Editor: Ahmed Zayed

Copyright (c) 2013 Sh. Rezapour and J. Hasanzade Asl. This is an open access article distributed under the Creative Commons Attribution License, which permits unrestricted use, distribution, and reproduction in any medium, provided the original work is properly cited.

In 2012, the notion of $\alpha-\psi$-contractive type mappings was introduced by Samet, C. Vetro, and P. Vetro. By using a simple method, we give some coupled fixed point results for $\alpha$ - $\psi$-contractive type mappings.

\section{Introduction}

In 1987, Guo and Lakshmikantham introduced the notion of coupled fixed points [1]. Then some authors proved some coupled fixed point results via some applications in the last decade of the previous century [2-6]. Later, this field was completed by some researchers by using different sights (see for example [7-18]). In 2012, Samet et al. introduced the notion of $\alpha-\psi$-contractive type mappings [19]. Also, AminiHarandi has provided a method for obtaining coupled fixed point results [20]. The aim of this paper is to provide a simple method for obtaining some coupled fixed point results for $\alpha$ $\psi$-contractive type mappings.

Denote by $\Psi$ the family of nondecreasing functions $\psi$ : $[0, \infty) \rightarrow[0, \infty)$ such that $\sum_{n=1}^{\infty} \psi^{n}(t)<\infty$ for all $t>0$ where $\psi^{n}$ is the $n$th iterate of $\psi$. It is known that $\psi(t)<t$ for all $t>0$ and $\psi \in \Psi$ [19]. Let $(X, d)$ be a metric space and $T$ a self-map on $X$. Then $T$ is called a $\alpha-\psi$-contraction mapping whenever there exist $\psi \in \Psi$ and $\alpha: X \times X \rightarrow[0, \infty)$ such that $\alpha(x, y) d(T x, T y) \leq \psi(d(x, y))$ for all $x, y \in X$ [19]. Also, we say that $T$ is $\alpha$-admissible whenever $\alpha(x, y) \geq 1$ implies $\alpha(T x, T y) \geq 1$ [19]. Also, we say that $X$ has the property $(B)$ if $\left\{x_{n}\right\}$ is a sequence in $X$ such that $\alpha\left(x_{n}, x_{n+1}\right) \geq 1$ for all $n \geq 1$ and $x_{n} \rightarrow x$, then $\alpha\left(x_{n}, x\right) \geq 1$ for all $n \geq 1$ [19]. Let $(X, d)$ be a complete metric space and T a $\alpha$-admissible $\alpha-\psi$ contractive mapping on $X$. Suppose that there exists $x_{0} \in X$ such that $\alpha\left(x_{0}, T x_{0}\right) \geq 1$. If $T$ is continuous or $X$ has the property (B), then $T$ has a fixed point (see [19]; Theorems 2.1 and 2.2). Also, we say that $X$ has the property $(H)$ whenever for each $x, y \in X$ there exists $z \in X$ such that $\alpha(x, z) \geq 1$ and $\alpha(y, z) \geq 1$. If $X$ has the property $(H)$ in the Theorems 2.1 and 2.2, then $X$ has a unique fixed point ([19]; Theorem 2.3). It is considerable that the results of Samet et al. generalize similar ordered results in the literature (see the results of third section in [19]). Let $F: X \times X \rightarrow X$ be a mapping, where $(X, d)$ is a metric space. We say that $\left(x_{0}, y_{0}\right) \in X \times X$ is a coupled fixed point of $F$ whenever $F\left(x_{0}, y_{0}\right)=x_{0}$ and $F\left(y_{0}, x_{0}\right)=y_{0}$. Define $T_{F}: X \times X \rightarrow X \times X$ by $T_{F}(x, y)=(F(x, y), F(y, x))$ for all $(x, y) \in X \times X$. Then, it is easy to check that $\left(x_{0}, y_{0}\right)$ is a coupled fixed point of $F$ if and only if $\left(x_{0}, y_{0}\right)$ is a fixed point of $T_{f}$.

\section{Main Results}

In this section, we define $\delta((x, y),(u, v))=d(x, u)+d(y, v)$ and

$$
\begin{aligned}
m((x, y),(u, v)) \\
=\max \{\delta((x, y),(u, v)), \delta((x, y),(F(x, y), F(y, x))), \\
\quad \delta((u, v),(F(u, v), F(v, u))),
\end{aligned}
$$




$$
\begin{aligned}
& \frac{1}{2}[\delta((x, y),(F(u, v), F(v, u))) \\
& \quad+\delta((u, v),(F(x, y), F(y, x)))]\}
\end{aligned}
$$

for all $(x, y),(u, v) \in X \times X$, where $(X, d)$ is a metric space and $F: X \times X \rightarrow X$ is a mapping. Now, we are ready to state and prove our main results.

Lemma 1. Let $(X, d)$ be a complete metric space, $\alpha: X \times X \rightarrow$ $[0, \infty)$ a function, $\psi \in \Psi$ and $T$ a self-map on $X$ such that

$$
\begin{array}{r}
\alpha(x, y) d(T x, T y) \\
\leq \psi(\max \{d(x, y), d(x, T x), d(y, T y), \\
\left.\left.\frac{1}{2}[d(x, T y)+d(y, T x)]\right\}\right)
\end{array}
$$

for all $x, y \in X$. Suppose that $T$ is $\alpha$-admissible and there exists $x_{0} \in X$ such that $\alpha\left(x_{0}, T x_{0}\right) \geq 1$. If $X$ has the property (B), then $T$ has a fixed point.

Proof. Take $x_{0} \in X$ such that $\alpha\left(x_{0}, T x_{0}\right) \geq 1$ and define the sequence $\left\{x_{n}\right\}$ in $X$ by $x_{n+1}=T x_{n}$ for all $n \geq 0$. If $x_{n}=$ $x_{n+1}$ for some $n$, then $x^{*}=x_{n}$ is a fixed point of $T$. Assume that $x_{n} \neq x_{n+1}$ for all $n$. Since $T$ is $\alpha$-admissible, it is easy to check that $\alpha\left(x_{n}, x_{n+1}\right) \geq 1$ for all $n \geq 1$. Thus, for each natural number $n$ one has

$$
\begin{aligned}
& d\left(x_{n}, x_{n+1}\right) \\
& =d\left(T x_{n-1}, T x_{n}\right) \leq \alpha\left(x_{n-1}, x_{n}\right) d\left(T x_{n-1}, T x_{n}\right) \\
& \leq \psi\left(\operatorname { m a x } \left\{d\left(x_{n}, x_{n-1}\right), d\left(x_{n}, x_{n+1}\right), d\left(x_{n-1}, x_{n}\right),\right.\right. \\
& \left.\left.\frac{1}{2}\left[d\left(x_{n}, x_{n}\right)+d\left(x_{n-1}, x_{n+1}\right)\right]\right\}\right) \\
& \leq \psi\left(\operatorname { m a x } \left\{d\left(x_{n}, x_{n-1}\right), d\left(x_{n}, x_{n+1}\right),\right.\right. \\
& \left.\left.\frac{1}{2}\left[d\left(x_{n}, x_{n-1}\right)+d\left(x_{n}, x_{n+1}\right)\right]\right\}\right) \\
& =\psi\left(\max \left\{d\left(x_{n}, x_{n-1}\right), d\left(x_{n}, x_{n+1}\right)\right\}\right) .
\end{aligned}
$$

If $\max \left\{d\left(x_{n}, x_{n-1}\right), d\left(x_{n}, x_{n+1}\right)\right\}=d\left(x_{n}, x_{n+1}\right)$, then

$$
d\left(x_{n+1}, x_{n}\right) \leq \psi\left(d\left(x_{n}, x_{n+1}\right)\right)<d\left(x_{n+1}, x_{n}\right)
$$

which is contradiction. Thus, $\max \left\{d\left(x_{n}, x_{n-1}\right), d\left(x_{n}, x_{n+1}\right)\right\}=$ $d\left(x_{n}, x_{n-1}\right)$ for all $n$. Hence, $d\left(x_{n+1}, x_{n}\right) \leq \psi\left(d\left(x_{n}, x_{n-1}\right)\right)$ and so $d\left(x_{n+1}, x_{n}\right) \leq \psi^{n}\left(d\left(x_{1}, x_{0}\right)\right)$ for all $n$. It is easy to check that $\left\{x_{n}\right\}$ is a Cauchy sequence. Thus, there exists $x^{*} \in X$ such that $x_{n} \rightarrow x^{*}$. By using the assumption, we have $\alpha\left(x_{n}, x^{*}\right) \geq 1$ for all $n$. Thus,

$$
\begin{aligned}
d\left(T x^{*}, x^{*}\right) & \\
\leq & d\left(T x^{*}, T x_{n}\right)+d\left(x_{n+1}, x^{*}\right) \\
\leq & \alpha\left(x_{n}, x^{*}\right) d\left(T x^{*}, T x_{n}\right)+d\left(x_{n+1}, x^{*}\right) \\
\leq & \psi\left(\operatorname { m a x } \left\{d\left(x_{n}, x^{*}\right), d\left(x_{n}, x_{n+1}\right), d\left(x^{*}, T x^{*}\right),\right.\right. \\
& \left.\left.\quad \frac{1}{2}\left[d\left(x_{n}, T x^{*}\right)+d\left(x^{*}, x_{n+1}\right)\right]\right\}\right) \\
= & \psi\left(\max \left\{d\left(x_{n}, x^{*}\right), d\left(x_{n}, x_{n+1}\right)\right\}\right)+d\left(x_{n+1}, x^{*}\right)
\end{aligned}
$$

for all $n$. Hence, $d\left(T x^{*}, x^{*}\right)=0$ and so $T x^{*}=x^{*}$.

By using a similar argument we can prove the following results.

Lemma 2. Let $(X, d)$ be a complete metric space, $\alpha: X \times X \rightarrow$ $[0, \infty)$ a function, $\psi \in \Psi$ and $T$ a continuous self-map on $X$ such that

$$
\begin{array}{r}
\alpha(x, y) d(T x, T y) \\
\leq \psi(\max \{d(x, y), d(x, T x), d(y, T y), \\
\left.\left.\frac{1}{2}[d(x, T y)+d(y, T x)]\right\}\right)
\end{array}
$$

for all $x, y \in X$. Suppose that $T$ is $\alpha$-admissible and there exists $x_{0} \in X$ such that $\alpha\left(x_{0}, T x_{0}\right) \geq 1$. Then $T$ has a fixed point.

Lemma 3. Let $(X, d)$ be a complete metric space, $\alpha: X \times X \rightarrow$ $[0, \infty)$ a function, $\psi \in \Psi$ and $T$ a self-map on $X$ such that

$$
\alpha(x, y) d(T x, T y) \leq \psi(d(x, u)+d(y, v))
$$

for all $x, y \in X$. Suppose that $T$ is $\alpha$-admissible and there exists $x_{0} \in X$ such that $\alpha\left(x_{0}, T x_{0}\right) \geq 1$. If $X$ has the property (B), then $T$ has a fixed point.

Lemma 4. Let $(X, d)$ be a complete metric space, $\alpha: X \times X \rightarrow$ $[0, \infty)$ a function, $\psi \in \Psi$ and $T$ a continuous self-map on $X$ such that

$$
\alpha(x, y) d(T x, T y) \leq \psi(d(x, u)+d(y, v))
$$

for all $x, y \in X$. Suppose that $T$ is $\alpha$-admissible and there exists $x_{0} \in X$ such that $\alpha\left(x_{0}, T x_{0}\right) \geq 1$. Then $T$ has a fixed point.

Theorem 5. Let $(X, d)$ be a complete metric space and $F$ : $X \times X \rightarrow X$ a mapping. Suppose that there exist a mapping $\alpha: X^{2} \times X^{2} \rightarrow[0,+\infty)$ and $\psi \in \Psi$ such that $\alpha((x, y)$, $(u, v)) d(F(x, y), F(u, v)) \leq(1 / 2) \psi(m((x, y),(u, v)))$ for all $(x, y),(u, v) \in X \times X, \alpha((x, y),(u, v)) \geq 1$ implies

$$
\alpha((F(x, y), F(y, x)),(F(u, v), F(v, u))) \geq 1
$$


for all $(x, y),(u, v) \in X \times X$ and there exists $\left(x_{0}, y_{0}\right) \in X \times X$ such that

$$
\alpha\left(\left(x_{0}, y_{0}\right),\left(F\left(x_{0}, y_{0}\right), F\left(y_{0}, x_{0}\right)\right)\right) \geq 1
$$

and $\alpha\left(\left(F\left(y_{0}, x_{0}\right), F\left(x_{0}, y_{0}\right)\right),\left(y_{0}, x_{0}\right)\right) \geq 1$. Also, suppose that for each convergent sequences $\left\{x_{n}\right\}$ and $\left\{y_{n}\right\}$ with $x_{n} \rightarrow x$, $y_{n} \rightarrow y, \alpha\left(\left(x_{n}, y_{n}\right),\left(x_{n+1}, y_{n+1}\right)\right) \geq 1$ and $\alpha\left(\left(y_{n+1}, x_{n+1}\right)\right.$, $\left.\left(y_{n}, x_{n}\right)\right) \geq 1$ for all $n$, we have $\alpha\left(\left(x_{n}, y_{n}\right),(x, y)\right) \geq 1$ and $\alpha\left((y, x),\left(y_{n}, x_{n}\right)\right) \geq 1$ for all $n$. Then $F$ has a coupled fixed point.

Proof. It is easy to check that $m((x, y),(u, v))=m((v, u)$, $(y, x))$ for all $(x, y),(u, v)$ in $X \times X$, the metric space $(X \times$ $X, \delta)$ is complete and $\beta(\xi, \eta) \delta\left(T_{F} \xi, T_{F} \eta\right) \leq \psi(m(\xi, \eta))$ for all $\xi=\left(\xi_{1}, \xi_{2}\right), \eta=\left(\eta_{1}, \eta_{2}\right) \in X \times X$, where

$$
\begin{aligned}
& \beta\left(\left(\xi_{1}, \xi_{2}\right),\left(\eta_{1}, \eta_{2}\right)\right) \\
& \quad=\min \left\{\alpha\left(\left(\xi_{1}, \xi_{2}\right),\left(\eta_{1}, \eta_{2}\right)\right), \alpha\left(\left(\eta_{2}, \eta_{1}\right),\left(\xi_{2}, \xi_{1}\right)\right)\right\} .
\end{aligned}
$$

Thus, $T_{F}$ is a $\beta$ - $\psi$-contractive mapping. It is easy to check that $T_{F}$ is $\beta$-admissible and $\beta\left(\left(x_{0}, y_{0}\right), T_{F}\left(x_{0}, y_{0}\right)\right) \geq 1$. Since $(X \times X, \delta)$ has the property $(B), T_{F}$ has a fixed point by using Lemma 1 and so $F$ has a coupled fixed point.

Theorem 6. Let $(X, d)$ be a complete metric space and $F$ : $X \times X \rightarrow X$ a continuous mapping. Suppose that there exist a mapping $\alpha: X^{2} \times X^{2} \rightarrow[0,+\infty)$ and $\psi \in \Psi$ such that $\alpha((x, y),(u, v)) d(F(x, y), F(u, v)) \leq(1 / 2) \psi(m((x, y),(u, v)))$ for all $(x, y),(u, v) \in X \times X, \alpha((x, y),(u, v)) \geq 1$ implies

$$
\alpha((F(x, y), F(y, x)),(F(u, v), F(v, u))) \geq 1
$$

for all $(x, y),(u, v) \in X \times X$ and there exists $\left(x_{0}, y_{0}\right) \in X \times X$ such that

$$
\alpha\left(\left(x_{0}, y_{0}\right),\left(F\left(x_{0}, y_{0}\right), F\left(y_{0}, x_{0}\right)\right)\right) \geq 1
$$

and $\alpha\left(\left(F\left(y_{0}, x_{0}\right), F\left(x_{0}, y_{0}\right)\right),\left(y_{0}, x_{0}\right)\right) \geq 1$. Then $F$ has a coupled fixed point.

Proof. The metric space $(X \times X, \delta)$ is complete and $\beta(\xi$, $\eta) \delta\left(T_{F} \xi, T_{F} \eta\right) \leq \psi(m(\xi, \eta))$ for all $\xi=\left(\xi_{1}, \xi_{2}\right), \eta=\left(\eta_{1}, \eta_{2}\right) \in$ $X \times X$, where

$$
\begin{aligned}
& \beta\left(\left(\xi_{1}, \xi_{2}\right),\left(\eta_{1}, \eta_{2}\right)\right) \\
& \quad=\min \left\{\alpha\left(\left(\xi_{1}, \xi_{2}\right),\left(\eta_{1}, \eta_{2}\right)\right), \alpha\left(\left(\eta_{2}, \eta_{1}\right),\left(\xi_{2}, \xi_{1}\right)\right)\right\} .
\end{aligned}
$$

Thus, $T_{F}$ is a continuous $\beta$ - $\psi$-contractive mapping. Also, it is easy to check that $T_{F}$ is $\beta$-admissible and $\beta\left(\left(x_{0}, y_{0}\right)\right.$, $\left.T_{F}\left(x_{0}, y_{0}\right)\right) \geq 1$. Now by using Lemma $2, T_{F}$ has a fixed point and so $F$ has a coupled fixed point.

Example 7. Let $X=[0,+\infty)$ and $d(x, y)=|x-y|$ for all $x, y \in X$. Define the mapping $F: X \times X \rightarrow X$ by $F(x, y)=$ $(x-y) / 4$ whenever $x \geq y$ and $F(x, y)=0$ whenever $x<y$.
Then $F$ is continuous mapping. Also, define $\alpha: X^{2} \times X^{2} \rightarrow$ $[0,+\infty)$ by

$$
\alpha((x, y),(u, v))= \begin{cases}1, & x \geq y, u \geq v \\ 0, & \text { otherwise }\end{cases}
$$

Thus, for each $(x, y),(u, v) \in X \times X$ we have

$$
\begin{aligned}
\alpha((x, y),(u, v)) d(F(x, y), F(u, v)) \\
\quad \leq|F(x, y)-F(u, v)|=\left|\frac{x-y}{4}-\frac{u-v}{4}\right| \\
=\frac{1}{4}|(x-u)+(v-y)| \leq \frac{1}{4}|x-u|+|v-y| \\
=\frac{1}{4}(d(x, u)+d(y, v)) \\
=\frac{1}{4} \delta((x, y),(u, v)) \leq \frac{1}{2} \psi(m((x, y),(u, v))),
\end{aligned}
$$

where $\psi(t)=t / 2$ for all $t \geq 0$. Also, it is easy to check that $\alpha((x, y),(u, v)) \geq 1$ implies $\alpha((F(x, y), F(y, x)),(F(u, v)$, $F(v, u))) \geq 1$ for all $(x, y),(u, v) \in X \times X$. Also, $\alpha\left(\left(x_{0}, y_{0}\right)\right.$, $\left.\left(F\left(x_{0}, y_{0}\right), F\left(y_{0}, x_{0}\right)\right)\right) \geq 1$ and $\alpha\left(\left(F\left(y_{0}, x_{0}\right), F\left(x_{0}, y_{0}\right)\right)\right.$, $\left.\left(y_{0}, x_{0}\right)\right) \geq 1$, where $\left(x_{0}, y_{0}\right)=(1,1)$. Thus by using Theorem $6, F$ has a coupled fixed point.

Corollary 8. Let $(X, d)$ be a complete metric space, $F: X \times$ $X \rightarrow X$ a mapping and $\leq$ an order on $X \times X$. Suppose that there exist $\left(x_{0}, y_{0}\right) \in X \times X$ such that $\left(x_{0}, y_{0}\right)$ and $\left(F\left(x_{0}, y_{0}\right), F\left(y_{0}, x_{0}\right)\right)$ are comparable and also $\left(y_{0}, x y_{0}\right)$ and $\left(F\left(y_{0}, x_{0}\right), F\left(x_{0}, y_{0}\right)\right)$ are comparable, and a mapping $\psi \in \Psi$ such that

$$
d(F(x, y), F(u, v)) \leq \frac{1}{2} \psi(m((x, y),(u, v)))
$$

for all comparable elements $(x, y),(u, v)$ in $X \times X$. Suppose that $(F(x, y), F(y, x))$ is comparable with $(F(u, v), F(v, u))$ whenever $(x, y)$ is comparable with $(u, v)$. Also, suppose that for each convergent sequences $\left\{x_{n}\right\}$ and $\left\{y_{n}\right\}$ with $x_{n} \rightarrow x$, $y_{n} \rightarrow y,\left(x_{n}, y_{n}\right)$ is comparable with $\left(x_{n+1}, y_{n+1}\right)$ and $\left(y_{n+1}\right.$, $\left.x_{n+1}\right)$ is comparable with $\left(y_{n}, x_{n}\right)$ for all $n$, one gets that $\left(x_{n}, y_{n}\right)$ is comparable with $(x, y)$ and $(y, x)$ is comparable with $\left(y_{n}, x_{n}\right)$ for all $n$. Then $F$ has a coupled fixed point.

Proof. Define the mapping $\alpha: X^{2} \times X^{2} \rightarrow[0,+\infty)$ by $\alpha((x, y),(u, v))=1$ whenever $(x, y)$ and $(u, v)$ are comparable and $\alpha((x, y),(u, v))=0$ otherwise. Then by using Theorem $5, F$ has a coupled fixed point.

Corollary 9. Let $(X, d)$ be a complete metric space, $F: X \times$ $X \rightarrow X$ a continuous mapping, $\left(x^{*}, y^{*}\right) \in X \times X$ a fixed element and $\preceq$ an order on $X \times X$. Suppose that there exist $\left(x_{0}, y_{0}\right) \in X \times X$ such that $\left(x_{0}, y_{0}\right),\left(y_{0}, x_{0}\right),\left(F\left(x_{0}, y_{0}\right)\right.$, $\left.F\left(y_{0}, x_{0}\right)\right)$ and $\left(F\left(y_{0}, x_{0}\right), F\left(x_{0}, y_{0}\right)\right)$ are comparable with $\left(x^{*}, y^{*}\right)$, and a mapping $\psi \in \Psi$ such that $d(F(x, y), F(u, v)) \leq$ $(1 / 2) \psi(m((x, y),(u, v)))$ for all $(x, y)$ and $(u, v)$ in $X \times X$ which are comparable with $\left(x^{*}, y^{*}\right)$. Assume that $(F(x, y), F(y, x))$ and $(F(u, v), F(v, u))$ are comparable with $\left(x^{*}, y^{*}\right)$ whenever $(x, y)$ and $(u, v)$ so are. Then $F$ has a coupled fixed point. 
Proof. Define the mapping $\alpha: X^{2} \times X^{2} \rightarrow[0,+\infty)$ by $\alpha((x, y),(u, v))=1$ whenever $(x, y)$ and $(u, v)$ are comparable with $\left(x^{*}, y^{*}\right)$ and $\alpha((x, y),(u, v))=0$ otherwise. Then by using Theorem $6, F$ has a coupled fixed point.

Theorem 10. Let $(X, d)$ be a complete metric space and $F$ : $X \times X \rightarrow X$ a mapping. Suppose that there exist a mapping $\alpha: X^{2} \times X^{2} \rightarrow[0,+\infty)$ and $\psi \in \Psi$ such that

$$
\begin{gathered}
\alpha((x, y),(u, v)) d(F(x, y), F(u, v)) \\
\leq \frac{1}{2} \psi(\delta((x, y),(u, v)))
\end{gathered}
$$

for all $(x, y),(u, v) \in X \times X, \alpha((x, y),(u, v)) \geq 1$ implies

$$
\alpha((F(x, y), F(y, x)),(F(u, v), F(v, u))) \geq 1
$$

for all $(x, y),(u, v) \in X \times X$ and there exists $\left(x_{0}, y_{0}\right) \in X \times X$ such that

$$
\alpha\left(\left(x_{0}, y_{0}\right),\left(F\left(x_{0}, y_{0}\right), F\left(y_{0}, x_{0}\right)\right)\right) \geq 1
$$

and $\alpha\left(\left(F\left(y_{0}, x_{0}\right), F\left(x_{0}, y_{0}\right)\right),\left(y_{0}, x_{0}\right)\right) \geq 1$. Also, suppose that for each convergent sequences $\left\{x_{n}\right\}$ and $\left\{y_{n}\right\}$ with $x_{n} \rightarrow x$, $y_{n} \rightarrow y, \alpha\left(\left(x_{n}, y_{n}\right),\left(x_{n+1}, y_{n+1}\right)\right) \geq 1$ and $\alpha\left(\left(y_{n+1}, x_{n+1}\right)\right.$, $\left.\left(y_{n}, x_{n}\right)\right) \geq 1$ for all $n$, one has $\alpha\left(\left(x_{n}, y_{n}\right),(x, y)\right) \geq 1$ and $\alpha\left((y, x),\left(y_{n}, x_{n}\right)\right) \geq 1$ for all $n$. Then $F$ has a coupled fixed point.

Proof. The metric space $(X \times X, \delta)$ is complete and $\beta(\xi, \eta) \delta\left(T_{F} \xi, T_{F} \eta\right) \leq \psi(\delta(\xi, \eta))$ for all $\xi=\left(\xi_{1}, \xi_{2}\right), \eta=$ $\left(\eta_{1}, \eta_{2}\right) \in X \times X$, where

$$
\begin{aligned}
& \beta\left(\left(\xi_{1}, \xi_{2}\right),\left(\eta_{1}, \eta_{2}\right)\right) \\
& \quad=\min \left\{\alpha\left(\left(\xi_{1}, \xi_{2}\right),\left(\eta_{1}, \eta_{2}\right)\right), \alpha\left(\left(\eta_{2}, \eta_{1}\right),\left(\xi_{2}, \xi_{1}\right)\right)\right\} .
\end{aligned}
$$

Thus, $\beta(\xi, \eta) d\left(T_{F} \xi, T_{F} \eta\right) \leq \psi(\delta(\xi, \eta))$ for all $\xi, \eta \in X \times$ $X$. Also, it is easy to check that $T_{F}$ is $\beta$-admissible and $\beta\left(\left(x_{0}, y_{0}\right), T_{F}\left(x_{0}, y_{0}\right)\right) \geq 1$. Since $(X \times X, \delta)$ has the property $(B), T_{F}$ has a fixed point by using Lemma 3 , and so $F$ has a coupled fixed point.

Theorem 11. Let $(X, d)$ be a complete metric space and $F$ : $X \times X \rightarrow X$ a continuous mapping. Suppose that there exist a mapping $\alpha: X^{2} \times X^{2} \rightarrow[0,+\infty)$ and $\psi \in \Psi$ such that $\alpha((x, y),(u, v)) d(F(x, y), F(u, v)) \leq(1 / 2) \psi(\delta((x, y),(u, v)))$ for all $(x, y),(u, v) \in X \times X, \alpha((x, y),(u, v)) \geq 1$ implies

$$
\alpha((F(x, y), F(y, x)),(F(u, v), F(v, u))) \geq 1
$$

for all $(x, y),(u, v) \in X \times X$ and there exists $\left(x_{0}, y_{0}\right) \in X \times X$ such that

$$
\alpha\left(\left(x_{0}, y_{0}\right),\left(F\left(x_{0}, y_{0}\right), F\left(y_{0}, x_{0}\right)\right)\right) \geq 1
$$

and $\alpha\left(\left(F\left(y_{0}, x_{0}\right), F\left(x_{0}, y_{0}\right)\right),\left(y_{0}, x_{0}\right)\right) \geq 1$. Then $F$ has $a$ coupled fixed point.
Proof. The metric space $(X \times X, \delta)$ is complete and $\beta(\xi, \eta) \delta\left(T_{F} \xi, T_{F} \eta\right) \leq \psi(\delta(\xi, \eta))$ for all $\xi=\left(\xi_{1}, \xi_{2}\right), \eta=$ $\left(\eta_{1}, \eta_{2}\right) \in X \times X$, where

$$
\begin{aligned}
& \beta\left(\left(\xi_{1}, \xi_{2}\right),\left(\eta_{1}, \eta_{2}\right)\right) \\
& \quad=\min \left\{\alpha\left(\left(\xi_{1}, \xi_{2}\right),\left(\eta_{1}, \eta_{2}\right)\right), \alpha\left(\left(\eta_{2}, \eta_{1}\right),\left(\xi_{2}, \xi_{1}\right)\right)\right\} .
\end{aligned}
$$

Thus, $\beta(\xi, \eta) d\left(T_{F} \xi, T_{F} \eta\right) \leq \psi(\delta(\xi, \eta))$ for all $\xi, \eta \in X \times X$. Also, it is easy to check that $T_{F}$ is a continuous $\beta$-admissible mapping and $\beta\left(\left(x_{0}, y_{0}\right), T_{F}\left(x_{0}, y_{0}\right)\right) \geq 1$. Now by using Lemma $4, T_{F}$ has a fixed point and so $F$ has a coupled fixed point.

Example 12. Let $X=\mathbb{R}$ and $d(x, y)=|x-y|$ for all $x, y \in X$. Define the mapping $F: X \times X \rightarrow X$ by $F(x, y)=(x-y) / 3+1$ whenever $x \geq y$ and $F(x, y)=0$ whenever $x<y$. Then $F$ is a discontinuous mapping. Define $\alpha: X^{2} \times X^{2} \rightarrow[0,+\infty)$ by

$$
\alpha((x, y),(u, v))= \begin{cases}1, & x \geq y, u \geq v \\ 0, & \text { otherwise }\end{cases}
$$

Thus, for each $(x, y),(u, v) \in X \times X$ we have

$$
\begin{aligned}
& \alpha((x, y),(u, v)) d(F(x, y), F(u, v)) \\
& \quad \leq|F(x, y)-F(u, v)|=\left|\frac{x-y}{3}-\frac{u-v}{3}\right| \\
& \quad=\frac{1}{3}|(x-u)+(v-y)| \leq \frac{1}{3}|(x-u)|+|(v-y)| \\
& =\frac{1}{3}(d(x, u)+d(y, v)) \\
& =\frac{1}{3} \delta((x, y),(u, v))=\frac{1}{2} \psi(\delta((x, y),(u, v))),
\end{aligned}
$$

where $\psi(t)=2 t / 3$ for all $t \geq 0$. Also, $\alpha((x, y),(u, v)) \geq 1$ implies

$$
\alpha((F(x, y), F(y, x)),(F(u, v), F(v, u))) \geq 1
$$

for all $(x, y),(u, v) \in X \times X$. Finally, $\alpha\left(\left(x_{0}, y_{0}\right),\left(F\left(x_{0}, y_{0}\right)\right.\right.$, $\left.\left.F\left(y_{0}, x_{0}\right)\right)\right) \geq 1$ and $\alpha\left(\left(F\left(y_{0}, x_{0}\right), F\left(x_{0}, y_{0}\right)\right),\left(y_{0}, x_{0}\right)\right) \geq 1$, where $\left(x_{0}, y_{0}\right)=(2,2)$. Thus by using Theorem $10, F$ has a coupled fixed point.

Corollary 13. Let $(X, d)$ be a complete metric space, $F$ : $X \times X \rightarrow X$ a mapping and $\preceq$ an order on $X \times X$. Suppose that there exists a mapping $\psi \in \Psi$ such that $d(F(x, y), F(u, v)) \leq(1 / 2) \psi(\delta((x, y),(u, v)))$ for all comparable elements $(x, y)$ and $(u, v)$ in $X \times X$. Suppose that there exists $\left(x_{0}, y_{0}\right) \in X \times X$ such that $\left(F\left(x_{0}, y_{0}\right), F\left(y_{0}, x_{0}\right)\right)$ and $\left(x_{0}, y_{0}\right)$ are comparable and also $\left(F\left(y_{0}, x_{0}\right), F\left(x_{0}, y_{0}\right)\right)$ and $\left(y_{0}, x_{0}\right)$ are comparable, $(F(x, y), F(y, x))$ is comparable with $(F(u, v), F(v, u))$ whenever $(x, y)$ is comparable with $(u, v)$ and for each sequences $\left\{x_{n}\right\}$ and $\left\{y_{n}\right\}$ in $X$ such that $x_{n} \rightarrow x$, $y_{n} \rightarrow y,\left(x_{n}, y_{n}\right)$ and $\left(x_{n+1}, y_{n+1}\right)$ are comparable elements of $X \times X$ for all $n,\left(x_{n}, y_{n}\right)$ and $(x, y)$ are comparable elements for all $n$. Then $F$ has a coupled fixed point. 
Proof. Define the mapping $\alpha: X^{2} \times X^{2} \rightarrow[0,+\infty)$ by $\alpha((x, y),(u, v))=1$ whenever $(x, y)$ and $(u, v)$ are comparable and $\alpha((x, y),(u, v))=0$ otherwise. Then by using Theorem $10, F$ has a coupled fixed point.

Corollary 14. Let $(X, d)$ be a complete metric space, $F$ : $X \times X \rightarrow X$ a continuous mapping, $\left(x^{*}, y^{*}\right) \in X \times X a$ fixed element and $\preceq$ an order on $X \times X$. Suppose that there exist $\left(x_{0}, y_{0}\right) \in X \times X$ such that $\left(x_{0}, y_{0}\right),\left(y_{0}, x_{0}\right)$, $\left(F\left(x_{0}, y_{0}\right), F\left(y_{0}, x_{0}\right)\right)$ and $\left(F\left(y_{0}, x_{0}\right), F\left(x_{0}, y_{0}\right)\right)$ are comparable with $\left(x^{*}, y^{*}\right)$, a mapping $\psi \in \Psi$ such that $d(F(x, y)$, $F(u, v)) \leq(1 / 2) \psi(\delta((x, y),(u, v)))$ for all $(x, y)$ and $(u, v)$ in $X \times X$ which are comparable with $\left(x^{*}, y^{*}\right)$. Assume that $(F(x, y), F(y, x))$ and $(F(u, v), F(v, u))$ are comparable with $\left(x^{*}, y^{*}\right)$ whenever $(x, y)$ and $(u, v)$ so are. Then $F$ has a coupled fixed point.

Proof. Define the mapping $\alpha: X^{2} \times X^{2} \rightarrow[0,+\infty)$ by $\alpha((x, y),(u, v))=1$ whenever $(x, y)$ and $(u, v)$ are comparable with $\left(x^{*}, y^{*}\right)$ and $\alpha((x, y),(u, v))=0$ otherwise. Then by using Theorem 11, $F$ has a coupled fixed point.

Now, we give an application of Lemma 1. In this way, we study the nonlinear fractional differential equation $D^{\alpha_{0}} x(t)+$ $D^{\beta_{0}} x(t)=f_{0}(t, x(t))$ for $t \in[0,1]$ via the two-point boundary value condition $x(0)=x(1)=0$, where $f_{0}:[0,1] \times \mathbb{R} \rightarrow$ $\mathbb{R}$ is a continuous function and $0<\beta_{0}<\alpha_{0}<1$. Recall that the Green function associated to the equation is given by $G(t)=t^{\alpha_{0}-1} E_{\alpha_{0}-\beta_{0}, \alpha_{0}}\left(-t^{\alpha_{0}-\beta_{0}}\right)$, where $E_{\alpha_{0}, \beta_{0}}$ is the twoparametric Mittag-Leffler function defined by

$$
E_{\left(\alpha_{0}, \beta_{0}\right)}(z)=\sum_{k=0}^{\infty} \frac{z^{k}}{\Gamma\left(k \alpha_{0}+\beta_{0}\right)}
$$

for $\alpha_{0}>0$ and $\beta_{0}>0$ (see $\left.[21,22]\right)$. Let $X=C_{\mathbb{R}}([0,1])$ and

$$
d(f, g)=\sup _{x \in[0,1]}|f(x)-g(x)|
$$

Now by considering some conditions, we give the following result about existence of solution of the nonlinear fractional differential equation.

Theorem 15. Suppose that

(i) there exist a function $\xi: \mathbb{R}^{2} \rightarrow \mathbb{R}$ and $\psi \in \Psi$ such that

$$
\left|f_{0}(t, a)-f_{0}(t, b)\right| \leq \alpha_{0} \psi(d(a, b))
$$

for all $t \in[0,1]$ and $a, b \in \mathbb{R}$ with $\xi(a, b) \geq 0$,

(ii) there exist $x_{0} \in X$ such that $\xi\left(x_{0}(t), \int_{0}^{t} G(t-s) f_{0}(s\right.$, $\left.\left.x_{0}(s)\right) d s\right) \geq 0$ for all $t \in[0,1]$, for each $t \in[0,1]$ and $x, y \in X, \xi(x(t), y(t)) \geq 0$ implies

$$
\xi\left(\int_{0}^{t} G(t-s) f_{0}(s, x(s)), \int_{0}^{t} G(t-s) f_{0}(s, y(s)) d s\right) \geq 0,
$$

(iii) if $\left\{x_{n}\right\}$ is a sequence in $X$ with $x_{n} \rightarrow x$ and $\xi\left(x_{n}\right.$, $\left.x_{n+1}\right) \geq 0$ for all $n$, then $\xi\left(x_{n}, x\right) \geq 0$ for all $n$.

Then the nonlinear fractional differential equation has at least one solution.

Proof. It is well known that $x \in X$ is a solution of the nonlinear fractional differential equation if and only if is a solution of the integral equation

$$
x(t)=\int_{0}^{t} G(t-s) f_{0}(s, x(s)) d s
$$

for all $t \in[0,1]$. Define the operator $F: X \rightarrow X$ by $F x(t)=$ $\int_{0}^{t} G(t-s) f_{0}(s, x(s)) d s$ for all $t \in[0,1]$. Thus, for finding a solution of the the nonlinear fractional differential equation it is sufficient we find a fixed point of the continuous operator $F$. Let $x, y \in \mathrm{X}$ be such that $\xi(x(t), y(t)) \geq 0$ for all $t \in[0,1]$. By using (i), we get

$$
\begin{aligned}
\mid F x( & t)-F y(t) \mid \\
= & \left|\int_{0}^{t} G(t-s)\left(f_{0}(s, x(s))\right)-f_{0}(s, y(s)) d s\right| \\
& \leq \int_{0}^{t}|G(t-s)|\left|f_{0}(s, x(s))-f_{0}(s, y(s))\right| d s \\
& \leq \int_{0}^{t}|G(t-s)| \alpha_{0} \psi(|x(s)-y(s)|) d s \\
& \leq \alpha_{0} \psi\left(\|x-y\|_{\infty}\right) \sup _{t \in I} \int_{0}^{t}|G(t-s)| d s \\
& \leq \psi\left(\|x-y\|_{\infty}\right) .
\end{aligned}
$$

Note that, $G(t)=t^{\alpha_{0}-1} E_{\alpha_{0}-\beta_{0}, \alpha_{0}}\left(-t^{\alpha_{0}-\beta_{0}}\right) \leq t^{\alpha_{0}-1}(1 /(1+$ $\left.\left.\left|-t^{\alpha_{0}-\beta_{0}}\right|\right)\right) \leq t^{\alpha_{0}-1}$ for all $t \in[0,1]$. Thus, $\sup _{t \in[0,1]} \int_{0}^{t} G(t-$ $s) d s \leq 1 / \alpha_{0}$. Now, define $\alpha: X \times X \rightarrow[0, \infty)$ by $\alpha(x, y)=1$ whenever $\xi(x(t), y(t)) \geq 0$ for all $t \in[0,1]$ and $\alpha(x, y)=0$ otherwise. Hence, $\alpha(x, y)\|F x-F y\|_{\infty} \leq \psi\left(\|x-y\|_{\infty}\right)$ and so

$$
\begin{array}{r}
\alpha(x, y) d(F x, F y) \\
\leq \psi(\max \{d(x, y), d(x, F x), d(y, F y), \\
\left.\left.\frac{1}{2}[d(x, F y)+d(y, F x)]\right\}\right)
\end{array}
$$

for all $x, y \in X$. Thus, $F$ is an $\alpha$ - $\psi$-contractive mapping. By using (iii), $\alpha(x, y) \geq 1$ implies $\alpha(F x, F y) \geq 1$. Therefore, $F$ is $\alpha$-admissible. From (ii), there exists $x_{0} \in C(I)$ such that $\alpha\left(x_{0}, F x_{0}\right) \geq 1$. Now by using (iv) and Lemma 1 , there exists $x^{*} \in X$ such that $F x^{*}=x^{*}$.

Similar to the work of Samet et al. [19], we say that the space $X$ has the property $\left(H^{*}\right)$ whenever for each $(x, y),(u, v) \in X \times X$ there exists $\left(z_{1}, z_{2}\right) \in X \times X$ such that $\alpha\left((x, y),\left(z_{1}, z_{2}\right)\right) \geq 1, \alpha\left(\left(z_{2}, z_{1}\right),(y, x)\right) \geq 1, \alpha((u, v)$, $\left.\left(z_{1}, z_{2}\right)\right) \geq 1$ and $\alpha\left(\left(z_{2}, z_{1}\right),(v, u)\right) \geq 1$. It is easy to check that 
if $X$ has the property $\left(H^{*}\right)$ in before results, then the mapping has a unique coupled fixed point.

If there is an order $\leq$ on $X$, then one can construct the order $\leqslant$ on $X \times X$ by $(x, y) \leqslant(u, v)$ whenever $x \leq u$ and $v \leq y$. By using this idea, it has been provided some coupled fixed point results for mixed monotone mappings on ordered metric spaces [7]. Let $(X, \preccurlyeq)$ be a partially ordered set and $F: X \times X \rightarrow X$ a mapping. We say that $F$ has the mixed monotone property whenever $x_{1} \leqslant x_{2}$ implies $F\left(x_{1}, y\right) \leqslant$ $F\left(x_{2}, y\right)$ and $y_{1} \leqslant y_{2}$ implies $F\left(x, y_{2}\right) \preccurlyeq F\left(x, y_{1}\right)$ for all $x, y \in$ $X$ [7]. Thus by considering the provided corollaries and the explanations in the text-body, we can obtain some similar coupled fixed point results for mixed monotone mappings as special case of above results. Finally, it has been published interesting fixed point results on metric spaces with a graph (see e.g., [23-26]). There is a connection between fixed point results on ordered metric spaces and fixed point results on metric spaces with a graph $[23,27]$. It is notable that one can get some similar coupled fixed point results on metric spaces with a graph.

\section{Acknowledgments}

The authors express their gratitude to the referees for their helpful suggestions which improved final version of this paper.

\section{References}

[1] D. Guo and V. Lakshmikantham, "Coupled fixed points of nonlinear operators with applications," Nonlinear Analysis, vol. 11, no. 5, pp. 623-632, 1987.

[2] S. S. Chang and Y. H. Ma, "Coupled fixed points for mixed monotone condensing operators and an existence theorem of the solutions for a class of functional equations arising in dynamic programming," Journal of Mathematical Analysis and Applications, vol. 160, no. 2, pp. 468-479, 1991.

[3] Y. Z. Chen, "Existence theorems of coupled fixed points," Journal of Mathematical Analysis and Applications, vol. 154, no. 1, pp. 142-150, 1991.

[4] S. Heikkilä and V. Lakshmikantham, "A unified theory for firstorder discontinuous scalar differential equations," Nonlinear Analysis, vol. 26, no. 4, pp. 785-797, 1996.

[5] S. Jingxian and L. Lishan, "Iterative method for coupled quasisolutions of mixed monotone operator equations," Applied Mathematics and Computation, vol. 52, no. 2-3, pp. 301-308, 1992.

[6] Y. Sun, "A fixed point theorem for mixed monotone operators with applications," Journal of Mathematical Analysis and Applications, vol. 156, no. 1, pp. 240-252, 1991.

[7] V. Berinde, "Generalized coupled fixed point theorems for mixed monotone mappings in partially ordered metric spaces," Nonlinear Analysis, vol. 74, no. 18, pp. 7347-7355, 2011.

[8] V. Berinde and M. Borcut, "Tripled fixed point theorems for contractive type mappings in partially ordered metric spaces," Nonlinear Analysis, vol. 74, no. 15, pp. 4889-4897, 2011.

[9] M. Borcut and V. Berinde, "Tripled coincidence theorems for contractive type mappings in partially ordered metric spaces," Applied Mathematics and Computation, vol. 218, no. 10, pp. 5929-5936, 2012.
[10] H. S. Ding, L. Li, and S. Radenovic, "Coupled coincidence point theorems for generalized nonlinear contraction in partially ordered metric spaces," Fixed Point Theory and Applications, vol. 2012, article 96, 10 pages, 2012.

[11] H. S. Ding and L. Li, "Coupled fixed point theorems in partially ordered cone metric spaces," Filomat, vol. 25, no. 2, pp. 137-149, 2011.

[12] W. S. Du, "Coupled fixed point theorems for nonlinear contractions satisfied Mizoguchi-Takahashi's condition in quasiordered metric spaces," Fixed Point Theory and Applications, vol. 2010, Article ID 876372, 9 pages, 2010.

[13] R. H. Haghi, S. Rezapour, and N. Shahzad, "Some fixed point generalizations are not real generalizations," Nonlinear Analysis, vol. 74, no. 5, pp. 1799-1803, 2011.

[14] X. Q. Hu and X. Y. Ma, "Coupled coincidence point theorems under contractive conditions in partially ordered probabilistic metric spaces," Nonlinear Analysis, vol. 74, no. 17, pp. 6451-6458, 2011.

[15] W. Long, B. E. Rhoades, and M. Rajovic, "Coupled coincidence points for two mappings in metric spaces and cone metric spaces," Fixed Point Theory and Applications, vol. 2012, article 66, 9 pages, 2012.

[16] N. V. Luong and N. X. Thuan, "Coupled fixed points in partially ordered metric spaces and application," Nonlinear Analysis, vol. 74, no. 3, pp. 983-992, 2011.

[17] H. K. Nashine and W. Shatanawi, "Coupled common fixed point theorems for a pair of commuting mappings in partially ordered complete metric spaces," Computers and Mathematics with Applications, vol. 62, no. 4, pp. 1984-1993, 2011.

[18] B. Samet and C. Vetro, "Coupled fixed point theorems for multi-valued nonlinear contraction mappings in partially ordered metric spaces," Nonlinear Analysis, vol. 74, no. 12, pp. 4260-4268, 2011.

[19] B. Samet, C. Vetro, and P. Vetro, "Fixed point theorems for $\alpha-\psi$ contractive type mappings," Nonlinear Analysis, vol. 75, no. 4, pp. 2154-2165, 2012.

[20] A. Amini-Harandi, "Coupled and tripled fixed point theory in partially ordered metric spaces with application to initial value problem," Mathematical and Computer Modelling. In press.

[21] D. Baleanu, H. Mohammadi, and S. Rezapour, "Positive solutions of a boundary value problem for nonlinear fractional differential equations," Journal of Mathematical Analysis and Applications, vol. 311, no. 2, pp. 495-505, 2005.

[22] D. Baleanu, H. Mohammadi, and S. Rezapour, "Some existence results on nonlinear fractional differentialequations," Philosophical Transactions of the Royal Society. In press.

[23] S. M. A. Aleomraninejad, S. Rezapour, and N. Shahzad, "Some fixed point results on a metric space with a graph," Topology and Its Applications, vol. 159, no. 3, pp. 659-663, 2012.

[24] I. Beg, A. R. Butt, and S. Radojević, "The contraction principle for set valued mappings on a metric space with a graph," Computers and Mathematics with Applications, vol. 60, no. 5, pp. 1214-1219, 2010.

[25] J. Jachymski, "The contraction principle for mappings on a metric space with a graph," Proceedings of the American Mathematical Society, vol. 136, no. 4, pp. 1359-1373, 2008.

[26] A. Nicolae, D. O’Regan, and A. Petruşel, "Fixed point theorems for singlevalued and multivalued generalized contractions in metric spaces endowed with a graph," Georgian Mathematical Journal, vol. 18, no. 2, pp. 307-327, 2011. 
[27] D. O’Regan and A. Petruşel, "Fixed point theorems for generalized contractions in ordered metric spaces," Journal of Mathematical Analysis and Applications, vol. 341, no. 2, pp. 1241-1252, 2008. 


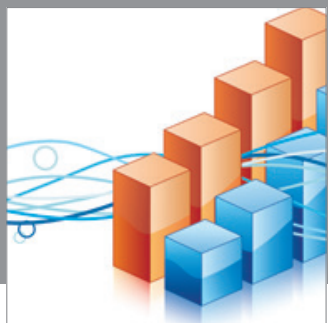

Advances in

Operations Research

mansans

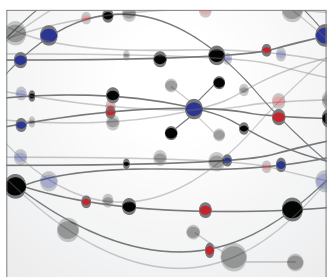

The Scientific World Journal
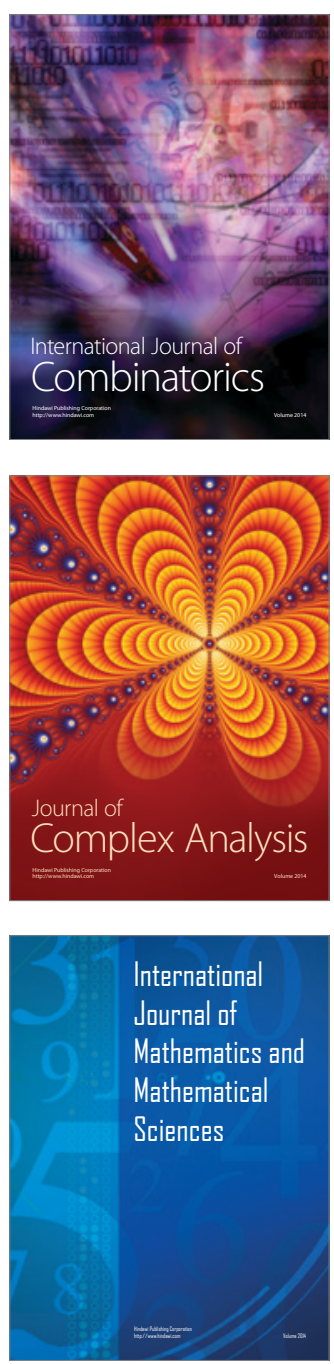
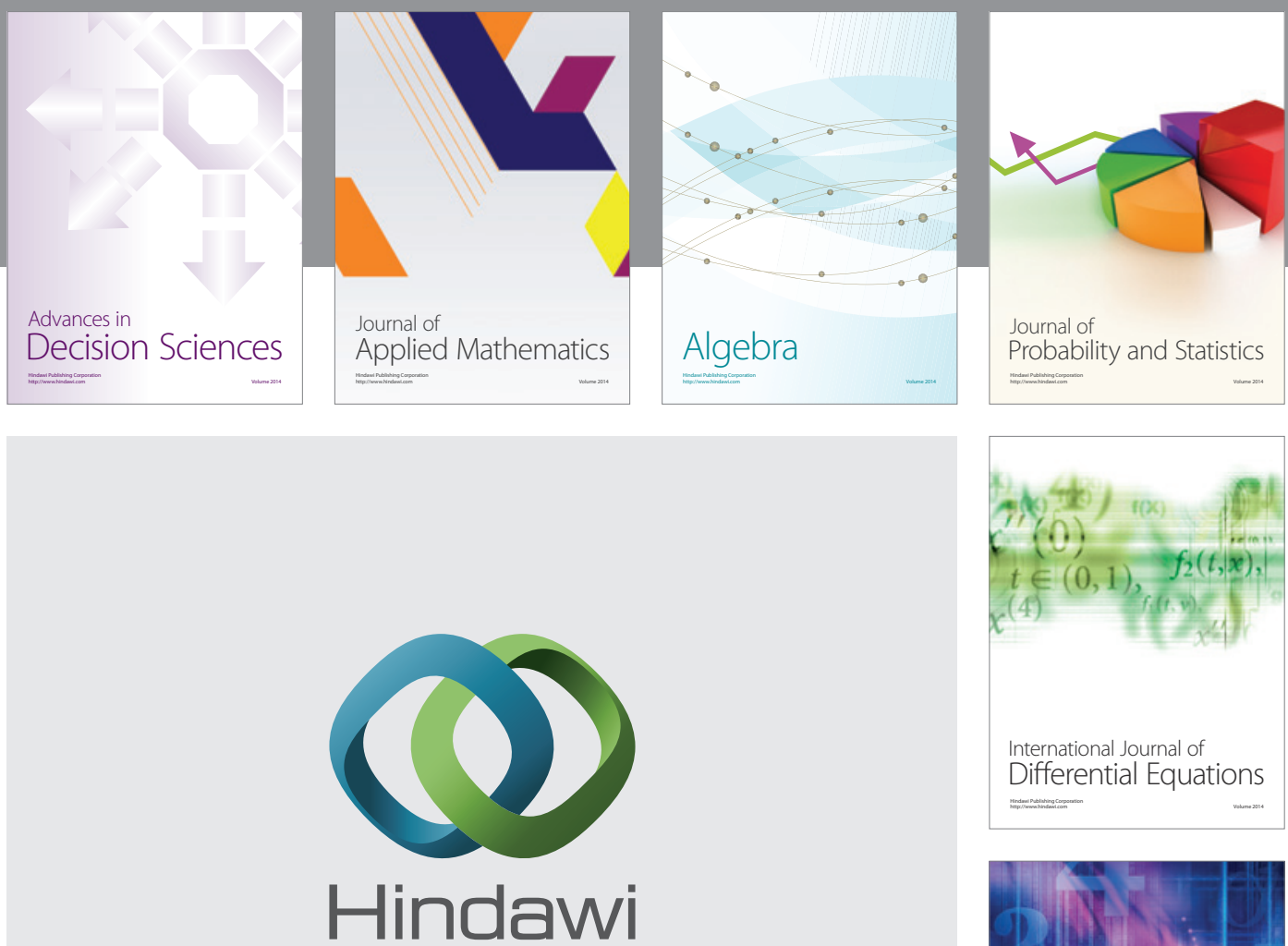

Submit your manuscripts at http://www.hindawi.com
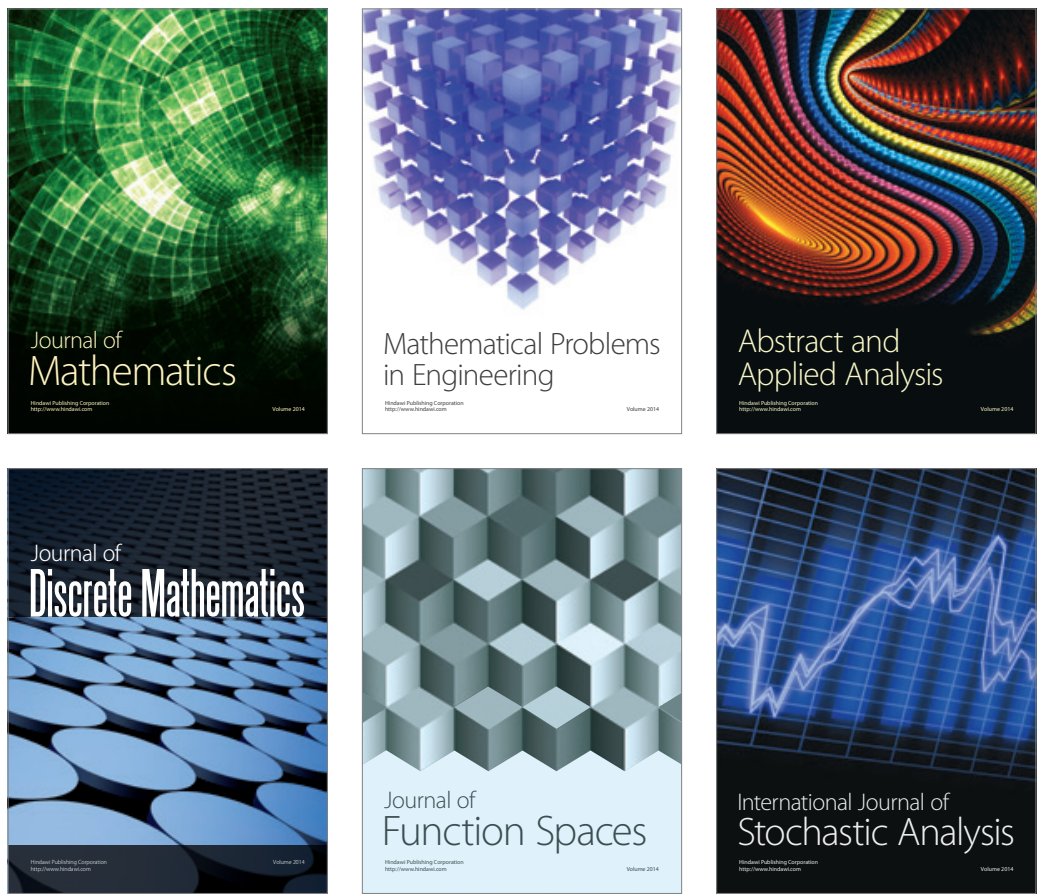

Journal of

Function Spaces

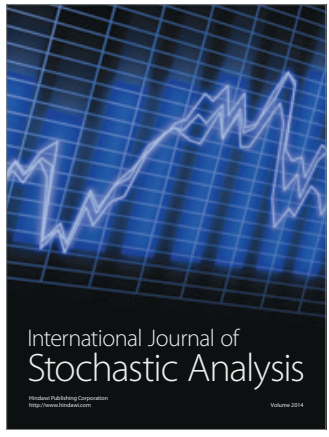

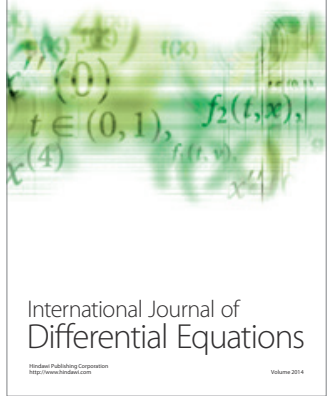
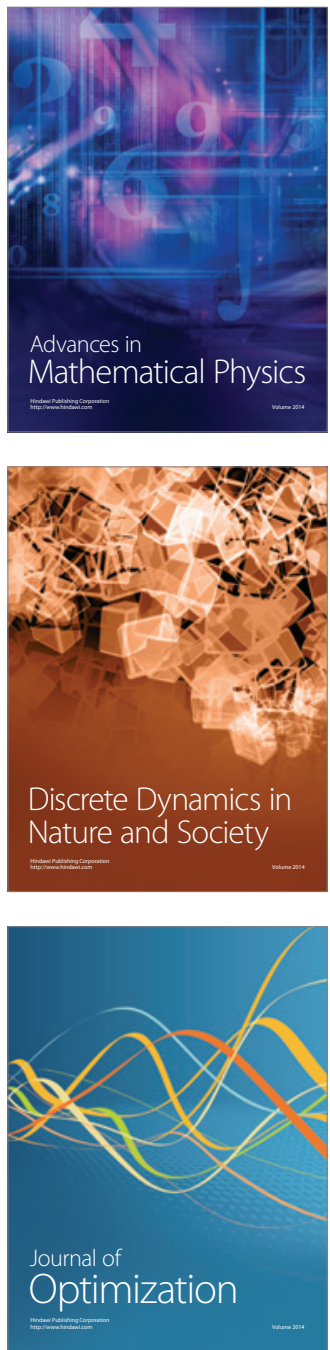